\title{
Joker in real life
}

\author{
Ildefonso Rodríguez-Leyva* and Carlos Abud-Mendoza \\ Hospital Central "Dr. Ignacio Morones Prieto", Faculty of Medicine, Universidad Autónoma de San Luis Potosí, San Luis Potosí, Mexico
}

The practice of medicine combines art and science, and those of us who enjoy the privilege of being medical professionals are rewarded with both professional and altruistic satisfaction in tending to the society we serve.

Many physicians share a passion for cinema and through this art, we try not only to distract our minds after bearing the great responsibilities our profession entails, but also, to learn from the characters that are presented in a film, whether reality or fiction.

Joker is undeniably an exceptional film, although the city, the characters, and the situation presented situation are totally fictitious, we cannot help but relate the film to what we are currently facing in our world today.

From the moment that the film begins, the main character reacts with laughter to the overwhelming social pressure, in which aggression, the lack of respect for the individual, bullying, mockery, and the enjoyment of others suffering, appear as social characteristics of a sick community. As medical doctors, we can recognize pathological characteristics in the main character, whom to justify his unreasonable, irrational, and uncontrollable laughter, displays a simple card with a warning that he suffers from a neurological problem that produces his spontaneous hilarity.

The explanation presented is that the main character suffers a history of severe cranial trauma with altered consciousness that had a permanent effect, leaving the
Joker with a disorder of inappropriate response which manifests as laughter.

Bilateral frontal damage can affect the bilateral corticonuclear system, causing the so-called pseudobulbar syndrome or loss of continence of emotions syndrome. Those who suffer from this syndrome can present a laugh or cry that is excessive and totally out of place, although it is difficult to believe that the person who suffers damage from the corticonuclear pathway (which regulates the motor nuclei of the brain stem, cranial nerves: III, IV, V, VI, VII, IX, X, XI, and XII) does not concomitantly suffer damage the corticospinal pathways. In the case of the Joker, in a manner uncharacteristic for such a brain-damaged patient, the character manages to dance down some stairs with enviable balance while wearing huge clown shoes.

In our professional practice, we had the honor of caring for a 35-year-old patient with Behcet's disease who presented these characteristics and that, during the development of his illness, suffered the loss of his 12-year-old daughter. At the funeral, our patient started laughing so uncontrollably and excessively that he decided to leave the funeral to avoid the judging eyes of those present who did not understand his laugh as a symptom of his condition in such an unfortunate scene.

Neurological involvement is a rare manifestation; it is one of the most serious causes of long-term morbidity, commonly associated to parenchymal affectation ${ }^{1-3}$.

\section{Correspondence:}

*lldefonso Rodríguez-Leyva

Hospital Central "Dr. Ignacio Morones Prieto"

Faculty of Medicine

Universidad Autónoma de San Luis Potosí

Date of reception: 16-01-2020

Date of acceptance: 17-01-2020

E-mail: ilrole @yahoo.com.mx

1665-5044/@ 2020. Academia Mexicana de Neurología A.C. Published by Permanyer. This is an open access article under the CC BY-NC-ND license
Available online: 02-03-2020 Rev Mex Neuroci. 2020;21(2):39-40 www.revmexneurociencia.com 
Fiction intertwined with reality and sometimes confusion overcomes us when our brain is injured and we are suffering from an inflammatory process as seemingly irrelevant as a simple urinary infection (often delirium is associated with this combination).

The reality of our patient produces both pathos and hope that humanity still exists in the face of societal violence. Our patient's reaction, unlike that of the Joker's, expresses his consciousness of his inappropriate behavior. Certainly, the actors, film directors, and the extras that cooperated to make Joker passionately lived each scene of such a great work of art. However, nothing compares to the physician's privilege of living our day-to-day interactions with both science and the art of medicine.

\section{References}

1. Sorgun $M H$, Kural MA, Yücesan $C$. Clinical characteristics and prognosis of Neuro-Behçet's disease. Eur J Rheumatol. 2018;5:235-9.

2. Al-Araji A, Kidd DP. Neuro-Behcet's disease: epidemiology, clinical characteristics, and management. Lancet Neurol. 2009;8:192-204.

3. Peño IC, De las Heras Revilla V, Carbonell BP, Di Capua Sacoto D, Ferrer ME, García-Cobos R, et al. Neurobehçet disease: Clinical and demographic characteristics. Eur J Neurol. 2012;19:1224-7. 